Federal Reserve Bank of Minneapolis

Research Department

\title{
Industry Evolution and Transition: The Role of Information Capital
}

\author{
Andrew Atkeson and Patrick J. Kehoe* \\ Working Paper 513 \\ Revised July 1993
}

\begin{abstract}
In this paper, we build a model of the transition following large-scale economic reforms that predicts both a substantial drop in output and a prolonged pause in physical investment as the initial phase of the optimal transition following the reform. We model reform as a change in policy which induces agents to close existing enterprises using old technologies of production and to open up new enterprises adopting new technologies of production. The central idea of our paper is that it is costly to close old enterprises and open new enterprises because, in doing so, information capital built up about old enterprises is lost and time must pass before information capital about new enterprises can be acquired. Thus, an acceleration of the pace of industry evolution leads in the short run to a net loss of information capital, a drop in productivity, a recession, and a fall in physical investment. We calibrate our model of industry evolution, information capital, and transition to match micro data on industry evolution in the United States and macro data from the United States, Japan, and the former communist countries of Europe. We find that the loss of information capital that accompanies a major acceleration in the pace of industry evolution in an economy leads initially to a decade of recession and a five year pause in physical investment before the benefits of reform are realized.
\end{abstract}

*Atkeson, University of Chicago and NBER; Kehoe, University of Pennsylvania and Federal Reserve Bank of Minneapolis. The views expressed herein are those of the authors and not necessarily those of the Federal Reserve Bank of Minneapolis or the Federal Reserve System. 


\section{Introduction}

Many countries that have undertaken large-scale economic reforms in recent years have experienced a prolonged recession and a large drop in investment in physical capital in the initial stages of the transition following reform. The World Bank's recent report (1992) on its structural adjustment lending programs documents this phenomenon in a wide variety of countries. More recently, Russia and the other former communist countries of Europe are undergoing severe recessions and large drops in investment after their reforms.

In this paper, we present one particular story why the process of restructuring an economy following a reform would begin with a drop in output and physical investment. We focus on the idea that a common consequence of the reforms undertaken in many of these countries is that the changes in policy induce enterprises in these economies to abandon old technologies of production and adopt new technologies. We build a quantitative model of the dynamics of technological and industry evolution during transition and use it to measure the extent to which these dynamics can result in a substantial recession and a prolonged pause in physical investment following reform. The central idea underlying our measurements is that it is costly for enterprises to abandon old technologies and adopt new technologies because, in doing so, something that we call information capital in old technologies is lost, and time must pass before new information capital in new technologies can be acquired. Thus, in our model, an acceleration in the pace of technological adoption in industry leads in the short run to a net loss of information capital, a drop in average productivity, a recession, and a fall in private investment.

Our model is constructed to highlight one aspect of transition and thus abstracts from a whole host of other aspects of reform and transition. Of course, transitions following actual reforms are shaped by many factors. Our main point is that, even abstracting from these other factors, the process of transition may naturally involve a turbulent period in which old, well understood ways of doing things are abandoned and new, untried and uncertain ones are adopted. Our measurements suggest that the costs of abandoning old information capital and acquiring new information capital are quantitatively important during transition.

Our concept of information capital begins with the notion that any time an enterprise adopts a new technology, there is considerable idiosyncratic uncertainty as to whether or not that particular enterprise will tend to be productive with that new technology over time. 
Since the future productivity of an enterprise that has adopted a new technology is not directly observable, the prospects for the productivity of any specific enterprise using a new technology can only be inferred by observing the track record of that individual enterprise over time. We call the stock of information that agents have acquired about the future productivity of the existing enterprises in the economy by observing the track records of those enterprises information capital.

Our model is a general equilibrium version of Jovanovic's (1982) model of industry evolution as a process of selection. In our model, the average productivity of the physical capital and labor employed in any group of enterprises adopting a new technology is initially low because agents in the economy lack the information capital necessary to allow them to distinguish enterprises with low expected productivity from those with high expected productivity. As these enterprises age and acquire track records, the average productivity of the capital and labor employed in these enterprises rises as agents remove capital and labor from those enterprises whose poor productivity prospects with the new technology are revealed by their track records and concentrate the physical capital and labor in those enterprises with proven productivity prospects with the new technology.

In our model, the enterprise, or the basic production unit in the economy, is identified with a manager and a choice of production technology. The output of the enterprise is a function of the choice of technology, the quality of the match between the manager and that technology, and the quantity of capital and labor employed in the enterprise. The productivity prospects of any enterprise using a given technology aro determined by the quality of the match between the manager and the technology - if the match is good, the enterprise is highly productive on average, if the match is bad, the enterprise is not. Each enterprise requires one manager with a limited span of control over physical capital and labor as in Lucas (1978) and uses only one technology during its life. We assume that the economy is subject to ongoing, exogenous technical change, so that all technologies eventually become obsolete and thus the process of technological adoption and selection continues even in the steady state of the model. We model the effects of reform as a sudden acceleration of the pace of technical change in the reforming economy driven by the process of opening the reforming economy to greater interaction with the rest of the world. This acceleration of the pace of technical change increases the incentives for enterprises 
to abandon old technologies and adopt new technologies and thus shapes the dynamics of information capital and the economy in the transition following reform.

To calibrate the model, we draw upon several different types of data: "steady state" observations from micro data on manufacturing plants in the United States as well as standard macro aggregates, "off-steady-state" data on the transition path of the postwar Japanese economy, and "initial condition" observations drawn from recent data on the Russia and Eastern Europe. In using the micro data from the United States, we identify enterprises abandoning old technologies as plant closures and enterprises adopting new technologies as plant openings. We use data drawn from the Census of Manufactures, compiled in Dunne, Roberts, and Samuelson (1989) and Davis and Haltiwanger (1991), on the failure rates of plants of different ages and on the fractions of the labor force employed in plants of different ages to calibrate the features of the technology for matching managers to technologies and of the manager's span of control technology. In particular, we choose the parameters of our model to be consistent with two important regularities from microeconomic data on manufacturing plants: failure rates of young plants are high and decline with age, and the employment of labor in old plants is a large fraction of total employment. We use standard U.S. macro aggregates to calibrate preferences, the aggregate production function, and the steady state growth rate of the world's technical knowledge. We use data on Japan's postwar economic growth to calibrate the acceleration in the rate of technical change that occurs in a country that undertakes a major reform. We then use data from Russia and Eastern European economies to set the initial conditions of the model and calculate the transition paths for these economies that results when they are faced with the same rate of technical change that was used in the model to reproduce the rapid growth in postwar Japan.

We use these data to conduct the following thought experiment. Suppose that, after reform, the market competition that gives rise to industry evolution in the U.S. is immediately transferred to Russia, and that the technology in Russia catches up to the world's technology at the same rate that, for Japan, reproduces its rapid growth experience. Then, what is Russia's transition path following reform? The point of this thought experiment is to starkly isolate the effect of information capital on transition. We find that when the initial conditions of the model are set to match data from Russia and Eastern Europe, there is a large recession and investment pause following reform. In the recession, output drops 
60 percent below its initial value and stays below this initial value for 11 years. Investment falls to zero during the transition, remaining there for 4 years, and does not attain its initial steady state ratio to output for 10 years. After the recession, the model economy grows steadily towards the U.S. level, moving from one quarter of U.S. output in the initial period of the transition to three quarters of U.S. output in about 44 years after the reform.

These results are driven by the optimal choices agents make to incur the costs of adopting new technologies. As the range of technical knowledge advances following reform, old technologies are abandoned as they quickly become obsolete. The managers, labor, and physical capital employed in those enterprises using the old technologies are moved into enterprises adopting new technologies. In the process of abandoning old technologies and adopting new ones, agents lose the information capital they had built up about enterprises using the old technologies and incur a loss in productivity in the short run in exchange for the long run gain in productivity that occurs when agents build up information capital about enterprises using the new technologies.

\section{The Economy}

Consider an economy in which time is discrete and indexed $t=0,1,2,3, \ldots, T$, with $T \leq \infty$. The economy is populated with two types of agents: a continuum of workers of measure $N$ and a continuum of managers of measure $M$, where $M+N=1$. Both types of agents have identical and homothetic preferences of the form

$$
\sum_{t=0}^{\infty} \beta^{t} u\left(c_{t}\right)
$$

Each manager is affiliated with one of a large number of coalitions of managers. Each coalition of managers is comprised of a measure $m$ of managers. There is a continuum of potential production technologies in this economy, with technologies indexed by $\tau \in[0, \infty)$. At each date $t$, managers in a coalition may operate production facilities or "plants" using any production technology indexed $\tau \leq \bar{\tau}_{i}$. The technology $\bar{\tau}_{t}$ is referred to as the frontier technology at date $t$. The frontier technology is assumed to evolve exogenously. Each plant requires one manager to operate it, so that the number of plants that a coalition of managers can operate is limited by the number of managers in the coalition. A plant using 
one manager, technology $\tau$, physical capital $k$, and workers $n$ has stochastic output

$$
\tau A(F(k, n))^{\nu}
$$

where $F$ is homogeneous of degree one and the parameter $\nu \in(0,1)$ corresponds to the span of control of a single manager as discussed in Lucas (1980). This technology has diminishing returns to scale in adding capital and labor to a plant, but has constant returns to scale in managers, workers, and capital. The productivity factor $A$ is random, distributed independently both across time and plants, and takes on one of $J$ realizations $\left\{A_{1}, \ldots, A_{J}\right\}$ with $A_{1}<A_{2}<\ldots<A_{J}$ in each period that the plant operates. The distribution of the productivity factor $A$ for a given plant depends upon the quality of the match between the manager and the technology in that plant. Each time a manager is matched with a new technology $\tau$ in a plant, the match between the manager and the technology in that plant may be either high quality or low quality, with $i=1,2$ indexing high and low quality matches respectively. For matches of quality $i$, productivity level $A_{j}$ is realized with probability $\pi_{i j}$ at each date that the plant operates. These probabilities satisfy $\sum_{k=1}^{j} \pi_{1 k} \leq \sum_{k=1}^{j} \pi_{2 k}$ for all $j=1,2, \ldots, J$, so that plants in which the manager and technology are well-matched have a higher probability of realizing higher productivity levels. The quality of an existing match between a manager and a technology cannot be observed directly. Rather, the quality of the match must be inferred from the plant's track record of production in previous periods. The posterior probability that the match between the manager and technology in a plant is high quality is determined recursively by Bayes Rule as follows: if $q_{t}$ is the prior in period $t$ that the match in that plant is high quality, and the plant experiences productivity level $A_{j}$ in period $t$, then the posterior probability in period $t+1$ that the match in that plant is high quality is

$$
q_{t+1}\left(q_{t}, A_{j}\right)=\frac{q_{t} \pi_{1 j}}{q_{t} \pi_{1 j}+\left(1-q_{t}\right) \pi_{2 j}}
$$

To change a match between a manager and a technology, the current match involving that manager must be dissolved and the plant run by that manager must be closed. The initial probability that any new match between any manager and any technology in a new plant is high quality is denoted by $\bar{q}$.

Agents in the economy derive information capital about the quality of the matches between managers and technologies for any coalition of managers from observing the history 
of production of the plants operated by that coalition of managers. We represent the information capital at date $t$ by a measure $\mu_{t}$ that summarizes all the information available about the quality of the matches between managers in a coalition and technologies in existing plants. Let $\rho_{t}=\tau / \tilde{\tau}_{t}$, denote the technology in a plant relative to the frontjer technology at date $t$. We let $\mu_{t}(\rho, q)$ denote the measure of managers who are in matches with technology $\tau=\rho \bar{\tau}$ and have track records of production giving posterior $q$ that the match is high quality.

A coalition of managers make decisions at $t$ that include choosing a measure of existing plants to operate in the current period, a measure of existing plants to close, and a measure of new plants to establish using the frontier technology $\bar{\tau}_{t}$. We denote the measure of plants operated by the coalition at $t$ by $\lambda_{t}(\rho, q)$, where

$$
0 \leq \lambda_{t}(\rho, q) \leq \mu_{t}(\rho, q)
$$

for all $(\rho, q) \neq(1, \bar{q})$, and

$$
\int_{\rho \times q} d \lambda_{t}(\rho, q) \leq m
$$

The measure of plants closed at $t$ is given by $(\mu(\rho, q)-\lambda(\rho, q))$ for $(\rho, q) \neq(1, \bar{q})$. The measure of new plants opened using technology $\bar{\tau}$ is included in $\lambda_{t}(1, \bar{q})$. The coalition of managers also decides on an allocation of physical capital and labor across plants operated in the current period denoted by $\left(k_{t}(\rho, q), n_{t}(\rho, q)\right)$. These decisions yield aggregate output for the coalition at date $t$ of

$$
\int_{\rho \times q} \bar{\tau}_{t} \rho E(A \mid q)\left(F\left(k_{t}(\rho, q), n_{t}(\rho, q)\right)\right)^{\nu} d \lambda_{t}(\rho, q)
$$

where

$$
E(A \mid q)=q \sum_{j=1}^{J} A_{j} \pi_{1 j}+(1-q) \sum_{j=1}^{J} A_{j} \pi_{2 j} .
$$

Since there is a continuum of plants managed by each coalition of managers, the aggregate output of a coalition of managers is deterministic.

We assume that the frontier technology evolves deterministically along a path $\left\{\bar{\tau}_{t}\right\}_{i=0}^{\infty}$. The coalition's decisions at $t$ to operate plants $\lambda_{t}(\rho, q)$ and the advance in technical knowledge from $\bar{\tau}_{t}$ to $\bar{\tau}_{t+1}$ determine the information capital $\mu_{t+1}(\rho, q)$ that the coalition will have at the beginning of period $t+1$ as follows. Every plant operating technology $\tau$ at time $t$ 
has $\rho_{t}=\tau / \bar{\tau}_{t}$ at date $t$ and $\rho_{t+1}=\rho_{t} \bar{\tau}_{t} / \bar{\tau}_{t+1}$ at date $t+1$. For plants with matches which had a prior $q_{t}$ of being high quality at time $t$, fraction $\pi_{j}\left(q_{t}\right)=q_{t} \pi_{1 j}+\left(1-q_{t}\right) \pi_{2 j}$ experience productivity level $A_{j}$ and thus those matches begin period $t+1$ with prior $q_{t+1}\left(q_{t}, A_{j}\right)$ of being high quality in period $t+1$. Thus, if we let

$$
q_{t}\left(q_{t+1}, A_{j}\right)=\frac{\pi_{2 j} q_{t+1}}{\pi_{2 j} q_{t+1}+\left(1-q_{t+1}\right) \pi_{1 j}}
$$

be the inverse of Bayes Rule when productivity level $A_{j}$ is realized, then there are

$$
\mu_{t+1}^{j}\left(\rho_{t+1}, q_{t+1}\right)=\pi_{j}\left(q_{t}\left(q_{t+1}, A_{j}\right)\right) \lambda_{t}\left(\rho_{t+1} \frac{\bar{\tau}_{t+1}}{\bar{\tau}_{t}}, q_{t}\left(q_{t+1}, A_{j}\right)\right)
$$

existing plants at $t+1$ with managers matched to technology $\rho_{t+1} \bar{\tau}_{t+1}$ that experienced productivity level $A_{j}$ in period $t$ and began period $t+1$ with prior $q_{t+1}$ that the match is high quality. The information capital of the coalition at period $t+1$ is then given by

$$
\mu_{t+1}(\rho, q)=\sum_{j=1}^{J} \mu_{t+1}^{j}(\rho, q) .
$$

For later use, we write the mapping from measures $\lambda_{t}$ and growth in $\tilde{\tau}$ into measures $\mu_{t+1}$ defined above as a function $S$, where

$$
\mu_{t+1}=S\left(\lambda_{t}, \bar{\tau}_{t+1} / \bar{\tau}_{t}\right)
$$

The aggregate amount of physical capital and labor used by a coalition at date $t$ is given by

$$
\begin{aligned}
& k_{t}=\int_{\rho \times q} k_{t}(\rho, q) d \lambda_{t}(\rho, q) \\
& n_{t}=\int_{\rho \times q} n_{t}(\rho, q) d \lambda_{t}(\rho, q) .
\end{aligned}
$$

Since the technology exhibits constant returns to scale, we consider the coalition of the whole as the representative coalition and set $m=M$. The aggregate resource constraint is

$$
c_{t}+x_{t} \leq y_{t}
$$

where $c_{t}$ and $x_{t}$ are aggregate consumption and investment respectively and where aggregate output $y_{t}$ is defined as

$$
y_{t}=\bar{\tau}_{t} \int_{\rho \times q} \rho E(A \mid q) F\left(k_{t}(\rho, q), n_{t}(\rho, q)\right)^{\nu} d \lambda_{t}(\rho, q) .
$$


The physical capital stock of the economy evolves according to

$$
k_{t+1}=(1-\delta) k_{t}+x_{t} .
$$

The resource constraints labor are

$$
n_{t} \leq N
$$

for all $t \geq 0$. Finally, we restrict

$$
c_{t}, x_{t} \geq 0
$$

for all $t$.

Since all agents have homothetic utility, the planning problem for this economy is to choose sequences of aggregate consumption and investment in physical capital $\left\{c_{t}, x_{t}\right\}_{t=0}^{\infty}$, measures of plants across technologies and priors and rules for allocating physical capital and labor across plants, $\left\{\lambda_{t}(\rho, q), k_{t}(\rho, q), n_{t}(\rho, q)\right\}_{t=0}^{\infty}$ to maximize the utility of the representative consumer (1.1) subject to the constraints (1.5), (1.6), (1.13), (1.16)-(1.19), taking initial conditions $\mu_{0}(\rho, q), k_{0}$ and the path of technical knowledge $\left\{\bar{\tau}_{t}\right\}_{t=0}^{\infty}$ as given.

Before we proceed with our analysis of equilibria in this economy, it is useful to discuss our interpretation of the assumptions we have made about knowledge acquisition and the process of matching managers and technologies. The variable $\bar{\tau}_{t}$ is intended to represent a country's stock of technical knowledge. In computing transitions in the model, we assume that before reform, government policies hindered the spillover of technical knowledge from the rest of the world and that after reform, technical knowledge spills over to the reforming country quickly, but not instantly. In the subsequent sections, we choose this rate of spillover to match the post-reform growth path of the model to Japan's postwar growth experience. We also assume that, while advances in technical knowledge enable managers to operate new technologies, there is considerable idiosyncratic variation in the quality of the match of each manager to each specific technology. Every time that a manager is matched to a new technology, the probability that the match is high quality is the same. It should be clear, then, that this matching process is not supposed to capture learning about inherent differences in the managers' abilities which apply to all technologies. Neither is it supposed to capture learning about the inherent quality of the technology itself in a manner which can be communicated across managers. Rather, these assumptions are intended to capture all of 
the idiosyncratic uncertainties encountered in establishing a new plant. These uncertainties include uncertainty about the relations between management, labor, technology, location, and markets, that is idiosyncratic to the matching of all of these factors in a new plant. Our model, of course, does not explicitly describe these features of the production process, but is meant to capture their flavor in a simple and tractable manner.

\section{Equilibrium}

In this section we decentralize the optimal allocation as a competitive equilibrium. We then characterize some features of the equilibrium that are useful for computation.

Consider first decentralizing the planning problem as a competitive equilibrium. Each coalition of managers solves the following problem. Given sequences of output prices, wages, rental rates on capital, frontier technologies, $\left\{p_{t}, w_{t}, r_{t}, \bar{\tau}_{t}\right\}_{t=0}^{\infty}$, and initial information capital $\mu_{0}$, the coalition chooses rules for allocating managers, capital, and labor across matches, $\left\{\lambda_{t}(\rho, q), k_{t}(\rho, q), n_{t}(\rho, q)\right\}_{t=0}^{\infty}$, to maximize

$$
\sum_{t=0}^{\infty} p_{t}\left[y_{t}-w_{t} n_{t}-r_{t} k_{t}\right]
$$

subject to constraints (1.5), (1.6), (1.13)-(1.15), (1.18) and (1.19).

Each worker solves the following problem. Given the sequence of prices and initial holdings of physical capital $k_{N 0}$, the worker chooses sequences of consumption and physical capital holdings $\left\{c_{N t}, k_{N t+1}\right\}_{t=0}^{\infty}$ to maximize

$$
\sum_{t=0}^{\infty} \beta^{t} u\left(c_{N t}\right)
$$

subject to

$$
\sum_{t=0}^{\infty} p_{t}\left[c_{N t}+k_{N t+1}\right]=\sum_{t=0}^{\infty}\left[w_{t}+\left(r_{t}+(1-\delta)\right) k_{N t}\right] .
$$

Each manager solves the following problem. Given the sequence of prices and initial holdings of physical capital $k_{M 0}$, the worker chooses sequences of consumption and physical capital holdings $\left\{c_{M t}, k_{M t+1}\right\}_{t=0}^{\infty}$ to maximize

$$
\sum_{t=0}^{\infty} \beta^{t} u\left(c_{M t}\right)
$$


subject to

$$
\sum_{t=0}^{\infty} p_{t}\left[c_{M t}+k_{M t+1}\right]=\sum_{t=0}^{\infty}\left[d_{t}+\left(r_{t}+(1-\delta)\right) k_{M t}\right],
$$

where dividends for the coalition of the whole, $\left\{d_{t}\right\}$, are defined by $d_{t}=y_{t}-w_{t} n_{t}-r_{t} k_{t}$.

A sequence of prices and allocations are a competitive equilibrium if they solve the coalition's problem, the worker's problem, the manager's problem, and if the allocation satisfies constraints (1.16)-(1.18) with $k_{t}=k_{N t} N+k_{M t} M, c_{t}=c_{N t} N+c_{M t} M, x_{t}=k_{t+1}-$ $(1-\delta) k_{t} \geq 0$. Since all agents have identical, homothetic utility functions, equilibrium prices and aggregate allocations are independent of the distribution of wealth across managers and workers.

It is useful to establish a simple feature of the competitive equilibrium. In particular, we show that the coalition's problem of allocating managers across matches with technologies in plants can be summarized by a cutoff rule: at every date $t$, for every technology there is a cutoff prior such that the coalition continues to operate all plants with that technology with priors above the cutoff and closes all plants with priors below the cutoff. Managers in plants that are closed move into new matches in new plants using the best available technology. This cutoff prior is higher for plants using technologies further behind the frontier technology. Furthermore, we show that at all dates $t$, there is a positive lower bound on the technologies that the coalition will operate.

To establish these results, consider the coalition's problem defined in equation (2.1) and the associated constraints. Since this problem is linear in the choice of $\left\{\lambda_{t}\right\}$, given a path for prices and the frontier technology, we can solve for the discounted stream of profits associated with any positive measure of managers in matches with technology $\rho$ at date $t$ with prior $q$ that those matches are high quality. This stream of profits is denoted by $v_{t}\left(\rho_{t}, q_{t}\right)$ and can be found recursively: for $\left(\rho_{t}, q_{t}\right) \neq(1, \bar{q})$

$$
\begin{gathered}
v_{t}\left(\rho_{t}, q_{t}\right)=\max \left[v_{t}(1, \bar{q}), D\left(\rho_{t}, q_{t}, w_{t}, r_{t}, \bar{\tau}_{t}\right)+\frac{p_{t+1}}{p_{t}} \sum_{j} \pi_{j}(q) v_{t+1}\left(\rho \frac{\bar{\tau}_{t}}{\bar{\tau}_{t+1}}, q_{t+1}\left(q_{t}, A_{j}\right)\right)\right], \\
v_{t}(1, \bar{q})=D\left(1, \bar{q}, w_{t}, r_{t}, \bar{\tau}_{t}\right)+\frac{p_{t+1}}{p_{t}} \sum_{j} \pi_{j}(\bar{q}) v_{t+1}\left(\frac{\bar{\tau}_{t}}{\bar{\tau}_{t+1}}, q_{t+1}\left(\bar{q}, A_{j}\right)\right),
\end{gathered}
$$

where $D(\rho, q, w, r, \bar{\tau})$ is the maximized value of the static dividend maximization problem, namely

$$
D(\rho, q, w, r, \bar{\tau})=\max _{k, n} \bar{\tau} \rho E(A \mid q)(F(k, n))^{\nu}-r k-w n
$$


The first term on the right hand side of (2.7) corresponds to the discounted present value of dividends that can be earned by closing a plant at $\left(\rho_{t}, q_{t}\right)$ and opening a new plant at the highest available technology $\bar{\tau}$. The second term on the right hand side of (2.7) corresponds to the discounted present value of dividends that can be earned by operating a plant at $\left(\rho_{t}, q_{t}\right)$ at date $t$ and following the optimal allocation strategy thereafter. Let $T<\infty$ be the terminal date for this economy. Then, from (2.7) we show the following:

Proposition 1: At each date $t<T$, given the sequence of prices and technical frontiers $\left\{p_{s}, w_{s}, r_{s}, \bar{\tau}_{s}\right\}_{s=t}^{T}$, the decision which plants to open and close can be summarized by a cutoff rule $q_{t}^{*}(\rho)$ which is weakly decreasing in $\rho$. Furthermore, there is a $\underline{\rho}>0$ such that $q_{t}^{*}(\rho)=1$ for all $\rho \leq \underline{\rho}$.

Proof: First observe that for any value of $\rho$, the static dividend function $D$ is increasing in $q$. Next observe that if, for all $\rho, v_{t+1}$ is weakly increasing in $q$, then our assumption that $\pi_{1}>\pi_{2}$ in the sense of first order stochastic dominance implies that the second term on the right hand side of (2.7) is increasing in $q$. Recall that a plant is closed only if $v_{t}\left(\rho_{t}, q_{t}\right)$ equals the first term on the right hand side of (2.7) and continues in operation if $v_{t}\left(\rho_{t}, q_{t}\right)$ is greater than the first term on the right hand side of (2.7). Since the first term on the right hand side of $(2.7)$ does not vary with $q$, the assumption that $v_{t+1}$ is weakly increasing in $q$ for each value of $\rho$ then implies that the decision to continue operating a plant or to close it obeys a cutoff rule in $q$ for each value of $\rho$. Since the static dividend function is increasing in $\rho$ for any value of $q$, if $v_{t+1}$ is also weakly increasing in $\rho$ for any value of $q$, then the cutoff prior is weakly decreasing in $\rho$. To get the result that for all $t, \rho$ and $q, v_{t+1}(\rho, \cdot)$ is weakly increasing in $q$ and $v_{t+1}(\cdot, q)$ is weakly increasing in $\rho$, observe first that since $T$ is the terminal date for the economy, $v_{T+1}=0$. Then observe that solving (2.7) backwards for $v_{t+1}$ for $t<T$ gives the required result. The result that there exists a $\underline{\rho}>0$ such that $q_{t}^{*}(\underline{\rho})=1$ follows from the fact that there exists some $\underline{\rho}>0$ such that $\underline{\rho} E(A \mid 1)<E(A \mid \bar{q})$, and thus the result that it cannot improve profits to keep open any positive measure of plant using technologies $\rho \leq \bar{\rho}$. This completes the proof. $f$

Note that proposition 1 can also be proved when $T=\infty$ and the economy settles down to a steady state growth path along which it is possible to show that $v_{t}(\rho, q)$ is weakly increasing in $\rho$ and $g$. We provide an example of such an economy in the next section. 


\section{Computation}

In this section, we discuss the method we use to compute equilibria of the model. First we discuss the method that we use to compute the steady state growth path of the model, and then we discuss the method we use for computing transition paths of the model.

In computing this model, we assume that $F(k, n)=k^{\theta} n^{(1-\theta)}$ and $u(c)=\log (c)$. Given aggregate capital stock, $k$, aggregate labor supply, $N$, and allocation of managers across technologies, $\lambda$, we solve for the optimal allocation of capital and labor across plants $\left(k_{t}(\rho, q), n_{t}(\rho, q)\right)$ within the period as a static problem. Doing so gives aggregate output $y$ as a function of $k, N, \lambda$ and $\bar{\tau}$ :

$$
y=\bar{\tau} A(\lambda)\left(k^{\theta} N^{(1-\theta)}\right)^{\nu}
$$

where

$$
A(\lambda)=\left[\int_{\rho \times q}(\rho E(A \mid q))^{1 /(1-\nu)} d \lambda(\rho, q)\right]^{(1-\nu)} .
$$

Note that $A(\lambda)$ is a simple one-dimensional statistic that effectively summarizes the impact of the information capital in operating plants on aggregate productivity in the current period. In our analysis of transition the path of $\left\{\lambda_{t}\right\}$ determines how the process of losing old information capital and building up new information capital affects the path of aggregate productivity. Taking the path of $\left\{\lambda_{t}\right\}$ as fixed, though, the predictions of this model for aggregate output, consumption, and investment are the same as those of a growth model with time-varying productivity. To the extent that the loss of information capital during transition leads to a decline in $\bar{\tau}_{t} A\left(\lambda_{t}\right)$, the predictions of this model for the path of aggregate output, consumption, and investment are equivalent to those of a growth model with negative productivity shocks.

A steady state growth path is a path for $\left\{\bar{\tau}_{t}\right\}_{t=0}^{\infty}$ growing at a constant rate $\left(1+\gamma_{\tau}\right)$ and a corresponding competitive equilibrium such that the sequences $\left\{\lambda_{t}, \mu_{t+1}, n_{t}, r_{t}, p_{t+1} / p_{t}\right\}_{t=0}^{\infty}$ are all constant and the sequences $\left\{y_{t}, c_{t}, k_{t}, k_{t+1}, x_{t}, w_{t}\right\}_{t=0}^{\infty}$ all grow at the same constant rate. To compute the steady state growth path of this parameterized version of this economy, we first calculate the steady state interest rate $R=p_{t} / p_{t+1}$, the rental rate on capital $r$,

and the steady state cutoff rule $q^{*}(\rho)$. Then we calculate the steady state measure of managers across plants and technologies $\lambda$, and finally, we calculate the steady state path 
for $\left\{y_{t}, c_{t}, k_{t}, k_{t+1}, x_{t}, c_{t}, w_{t}\right\}$. First, observe that in the steady state, the measure of managers across technologies and priors, $\lambda_{t}$, is constant, so the term $A\left(\lambda_{t}\right)$ is constant. The steady state growth rate of the economy $(1+\gamma)$ is given by $(1+\gamma)=\left(1+\gamma_{\tau}\right)^{1 /(1-\theta \nu)}$. The steady state interest rate is $R=(1+\gamma) / \beta$, and the steady state rental rate on capital $r=R-(1-\delta)$.

Consider next the computation of the steady state cutoff rule $q^{*}(\rho)$. First, along the steady state path, the maximal present discounted value of dividends associated with a positive measure of managers at a particular $(\rho, q)$ pair satisfies $v_{t+1}(\rho, q)=(1+\gamma) v_{t}(\rho, q)$. Furthermore, along the steady state growth path, since $\bar{\tau}$ grows at a constant rate, all managers are concentrated in technologies $\rho_{n}=\left(1+\gamma_{\tau}\right)^{-n}$ for $n=0,1,2, \ldots$. Thus, from (2.7), along the steady state path, $v_{0}(\rho, q)$ satisfies for $(\rho, q) \neq(1, \bar{q})$

$$
\begin{gathered}
v_{0}(\rho, q)=\max \left[v_{0}(1, \bar{q}), D\left(\rho, q, w_{0}, r, \bar{\tau}_{0}\right)+\beta \sum_{j} \pi_{j}(q) v_{0}\left(\rho\left(1+\gamma_{\tau}\right)^{-1}, q_{1}\left(q_{0}, A_{j}\right)\right)\right. \\
\left.v_{0}(1, \bar{q})=D\left(1, \bar{q}, w_{0}, r_{0}, \bar{\tau}_{0}\right)+\beta \sum_{j} \pi_{j}(\bar{q}) v_{0}\left(\left(1+\gamma_{\tau}\right)^{-1}, q_{1}\left(\bar{q}, A_{j}\right)\right)\right] .
\end{gathered}
$$

The steady state cutoff rule $q^{*}(\rho)$ is then determined by the relative size of the two terms on the right hand side of $(3.3)$.

To actually solve for the function $v_{0}(\rho, q)$, we first solve for the normalized value function

$$
\tilde{v}(\rho, q)=\frac{v_{0}(\rho, q)}{\bar{\tau}_{0}^{1 /(1-\nu)} w_{0}^{\nu \theta+(\nu / 1-\nu)}} .
$$

Given the form of the current dividend function $D, \tilde{v}$ satisfies (3.3) with $w_{0}=1, \bar{\tau}_{0}=1$, and $r$ set to its steady state value. We then iterate on guesses at $\tilde{v}(1, \bar{q})$ using this version of (3.3) to calculate $\bar{v}$ in the following fashion. Let $\bar{v}^{(0)}(1, \bar{q})$ be the first guess at the value of a new plant. For $n^{*}$ large enough, $\rho_{n^{*}} E(A \mid 1) \leq E(A \mid \bar{q})$, so $\tilde{v}^{(0)}\left(\rho_{n^{*}}, q\right)=\tilde{v}^{(0)}(1, \bar{q})$. Working backwards through the values of $\rho_{n}>\rho_{n^{*}}$ using $(3.3)$, we solve for $\bar{v}^{(0)}(\rho, q)$ for all $(\rho, q) \neq(1, \bar{q})$. Then we use $(3.3)$ for $(\rho, q)=(1, \bar{q})$ to generate a new guess for $\tilde{v}^{(1)}(1, \bar{q})$. We iterate on this procedure until $\bar{v}^{(n)}$ converges. We then use this normalized value function to find the steady state cutoff rule $q^{*}(\rho)$. For an example of a steady state cutoff rule, see Figure 1.

We use the steady state cutoff rule to generate the steady state measure $\lambda(\rho, q)$ in the following manner. In the steady state measure $\lambda$, all plants of the same age $n$ use 
the same technology $\rho_{n}$. Thus, we find $\lambda\left(\rho_{n}, q\right) / \lambda(1, \bar{q})$ by starting measure 1 plants at $(\rho, q)=(1, \bar{q})$ and then using $q^{*}(\rho)$ to calculate the measure of surviving plants of each age $n=0,1,2, \ldots, n^{*}$ across priors $q$. Finally, $\lambda(1, \bar{q})$, the measure of new plants starting each period in the steady state, is equal to the fraction of plant of all ages that fail as indicated by the cutoff rule $q^{*}(\rho)$. Once we have calculated the steady state measure $\lambda$, we calculate the steady state value of $A(\lambda)$, and the rest of the variables along the steady state path in the standard manner.

To calculate transitions in this model, we first choose a path for $\left\{\bar{\tau}_{t}\right\}$, for the country undergoing the transition. We begin with an initial $\bar{\tau}_{0}<\bar{\tau}_{0}^{W}$ where $\bar{\tau}_{0}^{W}$ is the best available technology in the world at date 0 . We assume that $\left\{\bar{\tau}_{i}^{W}\right\}$ grows at some constant rate $\left(1+\gamma_{\tau}\right)$. The path we choose for $\left\{\bar{\tau}_{t}\right\}_{t=0}^{\infty}$ converges over time to $\left\{\bar{\tau}_{t}^{W}\right\}_{t=0}^{\infty}$. We take initial conditions for $k_{0}$ and the measure $\mu_{0}$ and the path for technology $\left\{\bar{\tau}_{t}\right\}$ as given. We set a date $T+1$ by which time the equilibrium is constrained to jump to the steady state path. We then iterate on guesses at the transition path in the following manner.

We begin with a guess for the sequence of productivity factors $\left\{A_{t}^{(0)}\right\}_{t=1}^{T}$, where this sequence is a guess at the sequence $\left\{A\left(\lambda_{t}\right)\right\}_{t=1}^{T}$ that is generated in transition by the sequence of measures of operating plants $\left\{\lambda_{t}(\rho, q)\right\}_{t=1}^{T}$. Taking this first guess at the path for the productivity factors $\left\{\bar{\tau}_{t} A_{t}^{(0)}\right\}_{t=1}^{T}$ as fixed, we solve the model as a standard growth mode] with time varying productivity to obtain a first guess at the path for the aggregate capita] stock $\left\{k_{t+1}^{(0)}\right\}_{t=0}^{T}$ and the other aggregate variables in the economy. Using this transition path for the aggregate variables, we generate the path of prices $\left\{R_{t}^{(0)}, r_{t}^{(0)}, w_{t}^{(0)}\right\}_{t=0}^{T}$ implied by the first order conditions of the model. Given this guess at the sequence of prices, we calculate a first guess at the optimal sequence of measures $\left\{\lambda_{t}^{(0)}\right\}_{t=0}^{T}$ in the following manner. First, we assume that $v_{T+1}(\rho, q)$ is fixed at its value along the steady state path at $T+1$. We then use the price sequence $\left\{R_{t}^{(0)}, r_{t}^{(0)}, w_{t}^{(0)}\right\}_{t=0}^{T}$ and the sequence $\left\{\bar{\tau}_{t}\right\}$ to generate a sequence of value functions $\left\{v_{t}^{(0)}(\rho, q)\right\}_{t=0}^{T}$ and cutoff rules $\left\{q_{t}^{*(0)}(\rho)\right\}_{t=0}^{T}$ by backward induction using (2.7). With this guess at the cutoff rules and the initial measure $\mu_{0}$, we generate a sequence of measures $\left\{\lambda_{i}^{(0)}(\rho, q)\right\}_{i=0}^{T}$. This guess at the path of the measures of operating plants generates a new guess at the path of $A$ given by $A_{t}^{(1)}=A\left(\lambda_{t}^{(0)}\right)$ as defined in equation (3.2). We iterate on this procedure until the sequences $\left\{A_{t}^{(n)}, k_{t}^{(n)}\right\}_{t=1}^{T}$ converge. 


\section{Calibration}

In this section we discuss how we set the parameters of our model economy. We draw upon several different types of data: "steady state" observations from macro aggregates, "steady-state" micro observations on manufacturing plants in the United States, "off-steadystate" data on the transition path of the postwar Japanese economy, and "initial condition" observations drawn from recent data on the Russia and Eastern Europe.

We begin with preferences. The only parameter to choose is the discount factor, $\beta$, which is determined by the steady state first order condition $R=(1+\gamma) / \beta$. Here $R=$ $p_{t} / p_{t+1}$ is identified with the real return on investment in the U.S. economy and $\gamma$ is the growth rate of per capita GDP in the U.S. We set $R=1.0625$ and $\gamma=.02$, which gives $\beta=.96$.

The technology parameters include the parameters of the production function, $\theta$ and $\nu$, the parameters governing the stochastic component of productivity, $\left\{A_{j}\right\}, \pi_{1}, \pi_{2}$, and $\bar{q}$, and the process for the frontier technology in the country undergoing transition, $\left\{\bar{\tau}_{t}\right\}_{t=0}^{\infty}$. We parameterize this process for the frontier technology as

$$
\tilde{\tau}_{t}=\left(1+\gamma_{\tau}\right)^{t}\left(\alpha^{t} \bar{\tau}_{0}+\left(1-\alpha^{t}\right) \bar{\tau}_{0}^{W}\right)
$$

with parameters $\alpha, \bar{\tau}_{0}^{W}$, and $\bar{\tau}_{0}$. We normalize $\bar{\tau}_{0}^{W}=1$. Consider first $\theta$ and $\nu$. We assume that physical capital is paid its marginal product, and thus, the share of output paid to capital is $\theta \%$. We set this share to $1 / 3$. We set $\gamma_{\tau}$ to satisfy $\left(1+\gamma_{\tau}\right)=(1+\gamma)^{(1-\theta \nu)}$.

The parameters of the stochastic component of productivity $\left\{A_{j}\right\}, \pi_{1}, \pi_{2}, \vec{q}$, and the span of control parameter $\nu$ are determined using micro data on manufacturing plants drawn from the Census of Manufacturing. We use statistics on the failure rate of plants by age calculated by Dunne, Roberts, and Samuelson (1989) and statistics on the share of the labor force employed in plants of each age calculated by Davis and Haltiwanger (1991). We choose these parameters to match these statistics along the steady state growth path corresponding to $\gamma=.02$. In Table 1, we present these statistics calculated from the data and the corresponding statistics from the model economy.

The choice of the parameters $\alpha$, and $\bar{\tau}_{0}$ governing the path for $\left\{\bar{\tau}_{t}\right\}$ are not pinned down from steady state observations. We use off-steady-state data from Japan's growth path in setting $\alpha$ and $\bar{\tau}_{0}$. We choose these parameters together with initial parameters 
$k_{0}^{J}$ and $\mu_{0}^{J}$ to match Japan's postwar growth experience. The data on Japan's GNP per capita was obtained from Fumio Hayashi and is described in Hayashi (1989). First, we use the observation that Japan's prewar growth rate from 1925-1940 averaged approximately 3 percent a year to set $\mu_{0}(\rho, q)$ equal to the steady state information capital corresponding to a steady state growth rate of $\gamma=.03$. We assume that date 0 corresponds to 1945 . We assume that the initial capital stock in Japan, $k_{0}$, is $1 / 2$ of what it would have been along its prewar steady state growth path. We choose $\bar{\tau}_{0}$ and $\alpha$ so that output in the model economy for Japan equals the actual figure for 1950 and grows at a rate similar to that in the postwar Japanese data. For the path of technical knowledge $\left\{\bar{\tau}_{t}\right\}$ used in the Japan transition, see Figure 2. The path of output from the model economy and the data from 1947-1987 is presented in Figure 3.

Finally, to simulate transition for the Russian and Eastern European economies, we choose initial conditions for physical capital, technical expertise, and the initial information capital, namely $\tilde{\tau}_{0}, k_{0}$ and $\mu_{0}$, for these economies. Using the observation that Russia's growth rate of total factor productivity from 1960 to 1990 was negligible (see Kurtzweg (1987)), we set $\mu_{0}$ equal to the steady state stock of information capital corresponding to a steady state growth rate of the frontier technology of 0.2 percent per year. We then set $k_{0}$ equal to its steady state level, and we set $\bar{\tau}_{0}$ so that the output level along the pre-reform steady state path is one fourth the U.S. level at date zero of the simulation. We assume date zero corresponds to 1990 . For the path of technical knowledge $\left\{\bar{\tau}_{t}\right\}$ used in the Russia transition, see Figure 2. For a list of all the parameter values assumed, see Table 2.

In this calibration, we have used steady state micro data on industry evolution from the United States and off steady state data from Japan. We use these data to conduct the following thought experiment: suppose that, after reform, the market competition that gives rise to industry evolution in the U.S. is immediately transferred to Russia, and that the frontier technology in Russia catches up to the world frontier at a rate that reproduces Japan's rapid growth, then, what is Russia's transition path following reform. In choosing the initial conditions for the transition in this thought experiment, we think of the prereform policies in Russia as blocking the flow of technology from abroad but still allowing the selection process to shape industry evolution. When we present our findings, we discuss the effect of alternative assumptions about these initial conditions on the transition path. 
This thought experiment starkly isolates the effect of information capital on transition.

\section{Findings}

Consider first the transition path with the initial conditions set to approximate current conditions in Russia or Eastern Europe. In the first period of the reform, output rises slightly. At the same time, the ratio of investment to output rises slightly and the ratio of consumption to output falls. In the second period, output falls by over 60 percent, investment falls to zero and all of current output is consumed. (See Figures 4 and 5 for the path of output, and the ratio of consumption and investment to output in the first twenty years of transition.) In the next several periods, output slowly rises and attains its initial level about 11 years after the reform. Investment remains at zero for 4 years, and then rises, attains its initial ratio to output of 28 percent in about 15 years. During the next forty years, output grows steadily towards the U.S. steady state growth path, attaining 75 percent of the level of U.S. output about 44 years after the reform. (See Figure 6 for the ratio of Russian and U.S. output per capita over the first 50 years of transition.)

Our story for these results is as follows. Here, reform is modeled as a dramatic increase in the set of available technologies. Agent's decisions to adopt these technologies is governed by the fact that there is a both a cost and a benefit of adopting these new technologies. The benefit is that, for a given amount of information capital about matches between managers and technologies, the new technologies are more productive. The cost is that, initially, there is no information capital about these new technologies, and, since most new matches tend to be unproductive, the average productivity of physical capital and labor employed in the new plants is low. In the early stages of the transition, the set of available technologies increases so rapidly that the benefits of adopting new technologies relatively quickly outweigh the costs of losing information capital in existing matches. Thus, the cutoff rule rises and coalitions of managers choose to dissolve existing matches shortly after the reform. As the reform progresses, the growth in the frontier technology slows the cutoff rule converges to its steady state shape, and the information capital in the new plants grows to its steady state level. (See figure 7 for a picture of the cutoff rule during various stages of the transition). Aggregate productivity in this model is the product of the frontier technology $\bar{\tau}_{t}$ and the summary of information capital embodied in operating plants $A\left(\lambda_{t}\right)$. While the exogenous 
increase in the frontier technology that occurs in the early stages of transition acts to increase aggregate productivity, the loss of information capital that occurs when most old plants are shut down and new plants are opened is greater so that aggregate productivity, at least initially, falls quite dramatically. (See Figure 8 for a picture of the path of the frontier technology, the summary of information capital in existing plants, aggregate productivity, the product of these first two terms). The path of output, investment, and consumption that result are best understood as an optimal response to the large, temporary, drop in aggregate productivity that occurs in the early stages of the transition.

Consider next the implications of this model for industry evolution during transition in Russia. Recall that when we calibrated the model to the micro data on industry evolution in the United States, we identified enterprises abandoning old technologies as plant closings and enterprises adopting new ones as plant openings. We make this identifying assumption in light of institutional arrangements in the United States governing bankruptcy, unemployment, and plant closings. One can imagine that under alternative institutional arrangements, the government may be averse to closing plants officially in the state sector, allowing these plants to violate hard budget constraints to avoid causing open unemployment and bankruptcies. Under such arrangements, the same process of abandoning old technologies and rematching with new ones is carried out while still keeping plants officially open. In these circumstances, this rematching process will show up as a productivity decline in existing enterprises in the state sector and not as plant closings. If the government were to adopt institutional arrangement more like those in the U.S., then this model would predict a surge in plant closings and bankruptcies.

Now contrast this transition path with the one that arises when the initial conditions of the model are set to approximate those in Japan in 1945. (See figures 11 and 12 for the transition path of output and the ratio of investment and consumption to output). Qualitatively, the stages of the transition are similar, but, quantitatively, the investment pause and the recession are considerably smaller.

Two factors explain the difference in these transitions. The first factor is that countries which have slower growth rates before reform have more information capital built up about existing plants. In Figure 13, we plot the summary of information capital in operating plants, $A(\lambda)$, for steady state measures $\lambda$ corresponding to several different steady state 
growth rates. Given the assumption that Russia and Eastern Europe had a pre-reform growth rate of 0.2 percent per year, these countries have initial $A(\lambda)$ fifty percent higher than in the U.S. On the other hand, the assumption that Japan had a pre-reform growth rate of 3 percent per year implies that Japan has an initial $A(\lambda)$ which is 10 percent smaller than in the U.S. In both transitions, since all the old plants are closed in the second period of the transition, this information capital drops to the same level, namely that of new plants, $E(A \mid \bar{q})$. Thus, the initial drop in information capital in Japan is not as large as in Russia and the Eastern European countries. The second factor is that countries which start the reform with a small amount of physical capital relative to their technological frontier have a greater propensity to invest during transition so as to bring their capital stock in line with their level of technological expertise. Since we assume that Japan had a large fraction of its capital stock destroyed during the war, the investment pause in the Japanese transition is relatively short.

In calibrating our model, we chose one particular path for the flow of new technology into Russia following reform. Specifically, we chose the rate of technical change to match Japan's postwar growth experience. With this path, we found that there is a quantitatively large effect of information capital on the transition path. This effect can been seen in Figures 8 and 12. In Figure 8, we show the path of the Russian frontier technology, the summary of information capital, and the path of total factor productivity during transition. In a model with no information capital and a standard aggregate production function of the form $\bar{\tau}_{t} F\left(k_{t}, N\right)$, the path of the frontier technology is equal to the path of total factor productivity. Thus, the impact of information capital on productivity can be seen in this figure. In Figure 12, we show the path of output for Russia that results from the model with information capital and the path of output that results under the assumption that there is no information capital. This figure then shows that the impact of information capital on the path of output in the economy is quantitatively large.

Of course, there are other ways to choose the path for the frontier technology in Russia during the transition. For example, one might choose a path in which the new technologies flow in much more quickly. This choice would lead to a smaller recession, however, we argue that there would still be a quantitatively large effect of information capital on the transition path in comparison to a model with no information capital. In particular, there would be 
a large gap between the two models in the paths of both productivity and output.

\section{Conclusion}

This paper focuses on only one aspect of the transition following reform. It emphasizes the tradeoff agents face in adopting new technologies - the long run benefits of using more sophisticated technology must be weighed against the short run costs of the loss of information capital that occurs when old technologies are abandoned. We abstract from a whole host of other aspects of transition including, among others, market imperfections, policy problems, and shocks to the trading system. For example, Calvo and Coricelli (1992) argue that inappropriate credit policies by the government play an important role in exacerbating recession following reform in many countries. We found that, even without these other problems, the process of abandoning old information capital and acquiring new information capital following reform can lead to a deep recession and a prolonged investment pause in the early stages of transition.

One particularly important aspect of reform that we do not consider is the effect it can have on the incentives to use existing technologies more efficiently. A model which focused exclusively on this aspect may lead to very different predictions, such as an initial boom in output and investment. The transitions following actual reforms, of course, are influenced by many factors. Perhaps China's agricultural reform, which led very quickly to large increases in agricultural output, had a greater effect on the incentives to farm efficiently using existing technology than it did on the incentives to adopt new technologies.

For reasons of tractability, we have kept the model in this paper very simple. It would be interesting to extend this model in various dimensions. For instance, in the model, we assume that physical capital is malleable across technologies, thus abandoning old technologies does not require that physical capital be scrapped. Including technology-specific, or vintage, capital would add an additional cost of abandoning old technologies and would also require new investment to adopt new technologies. This might slow down the adoption of new technologies and lessen the investment pause. In the model we assume that the technological frontier grows exogenously. Extending the model to make the growth of the frontier technology depend on endogenous investments in the technical expertise of each coalition of managers as in Parente and Prescott (1992) may well slow down transition and reduce the 
drop in output and physical investment. In this model, we have not allowed plants to update technology without a loss of information capital. One can imagine extending the model to distinguish between fundamental and incremental changes in technology (as in Jovanovic and Rob (1990)), allowing plants to make investments in incremental improvements in their basic technology without losing information capital. Along these lines, Pakes and Ericson (1989) present an alternative model of industry evolution driven by plant's investments in improving their own technologies. Finally, it would be straightforward to allow for learning by doing within the context of an individual match to allow for increases in productivity at the level of the individual plant. 


\section{References}

Calvo, Guillermo and Fabrizio Coricelli [1992], "Output Collapse in Eastern Europe: The Role of Credit," Unpublished, International Monetary Fund.

Davis, Steve J. and John Haltiwanger [1991], "Gross Job Creation, Gross Job Destruction, and Employment Reallocation," Working Paper 3728, NBER.

Dunne, Timothy, Mark Roberts, and Larry Samuelson [1989], "The Growth and Failure of U.S. Manufacturing Plants," Quarterly Journal of Economics, Vol. 104, pp. 671-698.

Hayashi, Fumio [1989], "Japan's Saving Rate: New Data and Reflections," Working Paper 3205, NBER.

Jovanovic, Boyan [1982], "Selection and the Evolution of Industry," Econometrica, Vol. 50 no. 3 , pp. 649-670.

Jovanovic, Boyan and Rafael Rob [1990], "Long Waves and Short Waves: Growth through Intensive and Extensive Search," Econometrica, Vol. 58 no. 6, pp. 13911409 .

LuCAs, Robert E., JR. [1978], "On the Size Distribution of Business Firms," The Bell Journal of Economics, Vol. 9, pp. 508-523.

Pakes, Ariel, And Richard Ericson [1989], "An Alternative Model of Firm and Industry Dynamics," Unpublished, Yale University.

Parente, Stephen, and Edward Prescott [1992], "Technology Adoption and Growth," Unpublished, University of Minnesota.

KurtzweG, Laurie [1987], "Trends in Soviet Gross National Product." In U.S. Congress, Joint Economic Committee, Gorbachev's Economic Plans, 100th Congress S.Prt. 100-57, Volume 1 November 23, 1987. 
Table 1

\section{Plant Failure Rates}

Age(Years)

\begin{tabular}{llll}
\hline & $1-5$ & $6-10$ & $11-15$ \\
\hline Dunne et. al. & .397 & .303 & .255 \\
Model & .383 & .315 & .226 \\
\hline
\end{tabular}

Employment Share By Age of Plant

\begin{tabular}{lcccccccc} 
& \multicolumn{7}{c}{ Age(Years) } \\
& 0 & 1 & 2 & 3 & $4-5$ & $6-10$ & $11-14$ & $15+$ \\
& & & & & & & & \\
& & & & & & & \\
& & 1.8 & 1.5 & 1.5 & 4.5 & 14.3 & 11.0 & 64.5 \\
Davis et. al. & 0.8 & 1.4 & 1.6 & 1.8 & 4.2 & 12.0 & 10.0 & 67.9 \\
Model & 1.1 & & & & & & & \\
\hline
\end{tabular}


Table 2

\section{Parameters}

\begin{tabular}{|c|c|c|}
\hline Preference: & $\beta=0.96$ & (Discount Factor) \\
\hline \multirow[t]{4}{*}{ Production: } & $\theta=2 / 3$ & (Capital Coefficient) \\
\hline & $\nu=1 / 2$ & (Span of Control) \\
\hline & $\delta=0.08$ & (Depreciation Rate) \\
\hline & $\gamma=0.02$ & (Steady State Growth Rate) \\
\hline \multirow[t]{2}{*}{ Technology: } & $\alpha=2 / 3$ & (Rate of Technical Convergence) \\
\hline & $\bar{\tau}_{0}^{W}=1$ & (Initial Value of World Technology) \\
\hline \multirow[t]{4}{*}{ Matching: } & $A=(1 e-5,2 e-5,3 e-5,1)$ & (Productivity Realizations) \\
\hline & $\pi_{1}=(.015, .453, .458, .074)$ & (Good Match) \\
\hline & $\pi_{2}=(.130, .435, .435,0)$ & (Bad Match) \\
\hline & $\bar{q}=0.2$ & (Probability New Match is Good) \\
\hline
\end{tabular}


Figure 1: S.S. Cutoff Rule 2 percent Growth

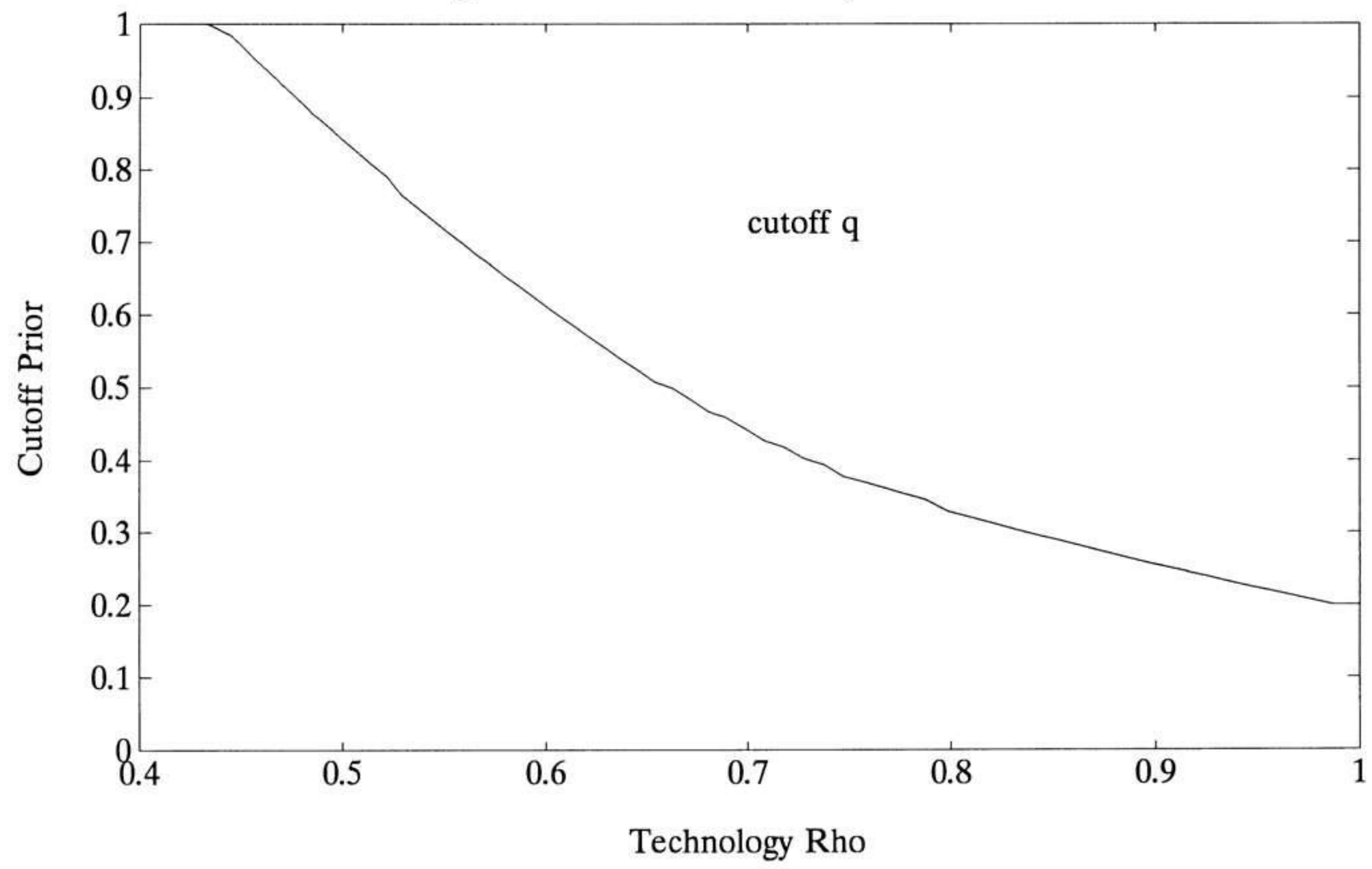

Figure 2: Russia and Japan Path of Taubar Pre and Post Reform

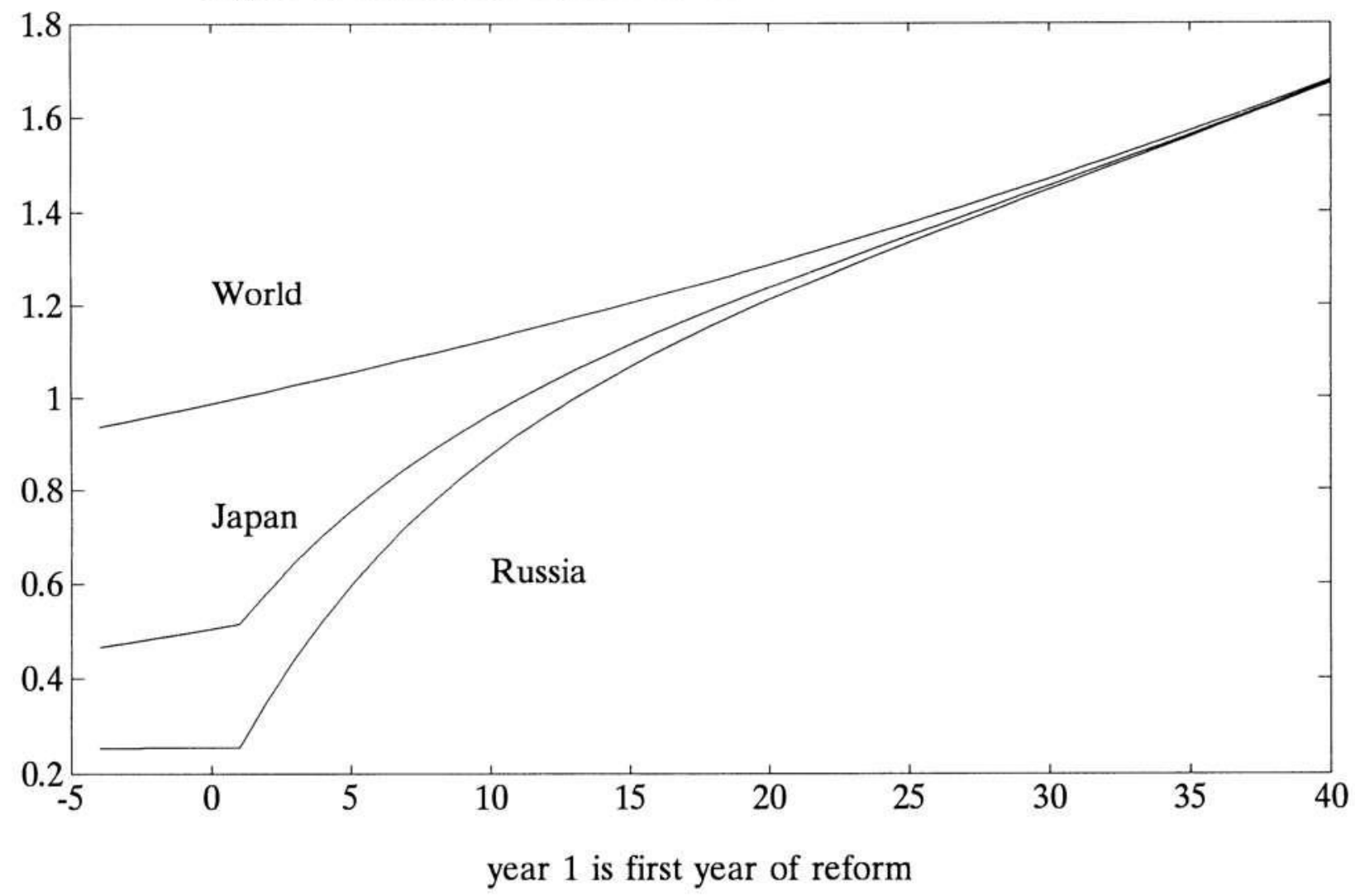


Figure 3: Log of Japanese Output 1947-1987, Data and Model

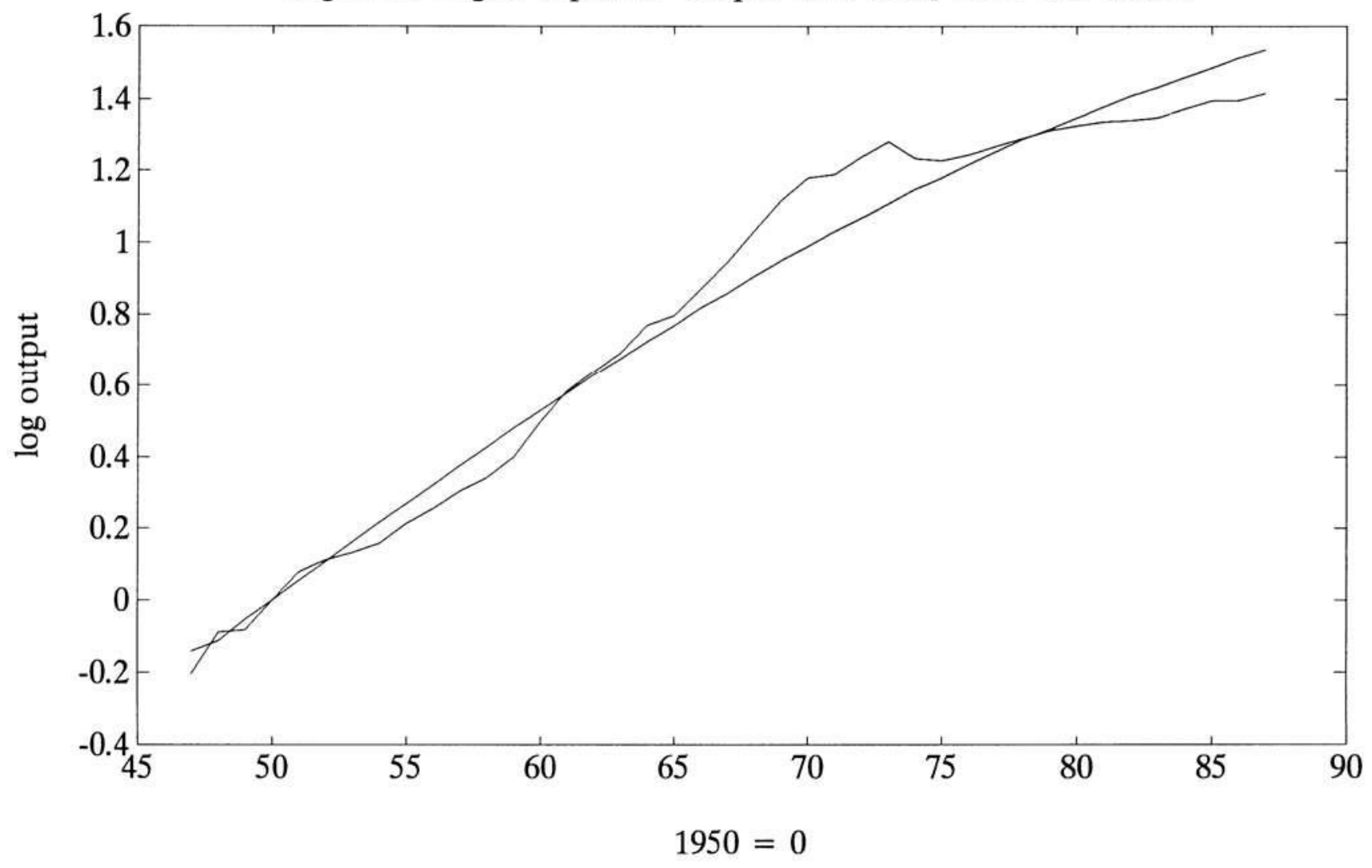

Figure 4: Russia - Twenty Years of Output

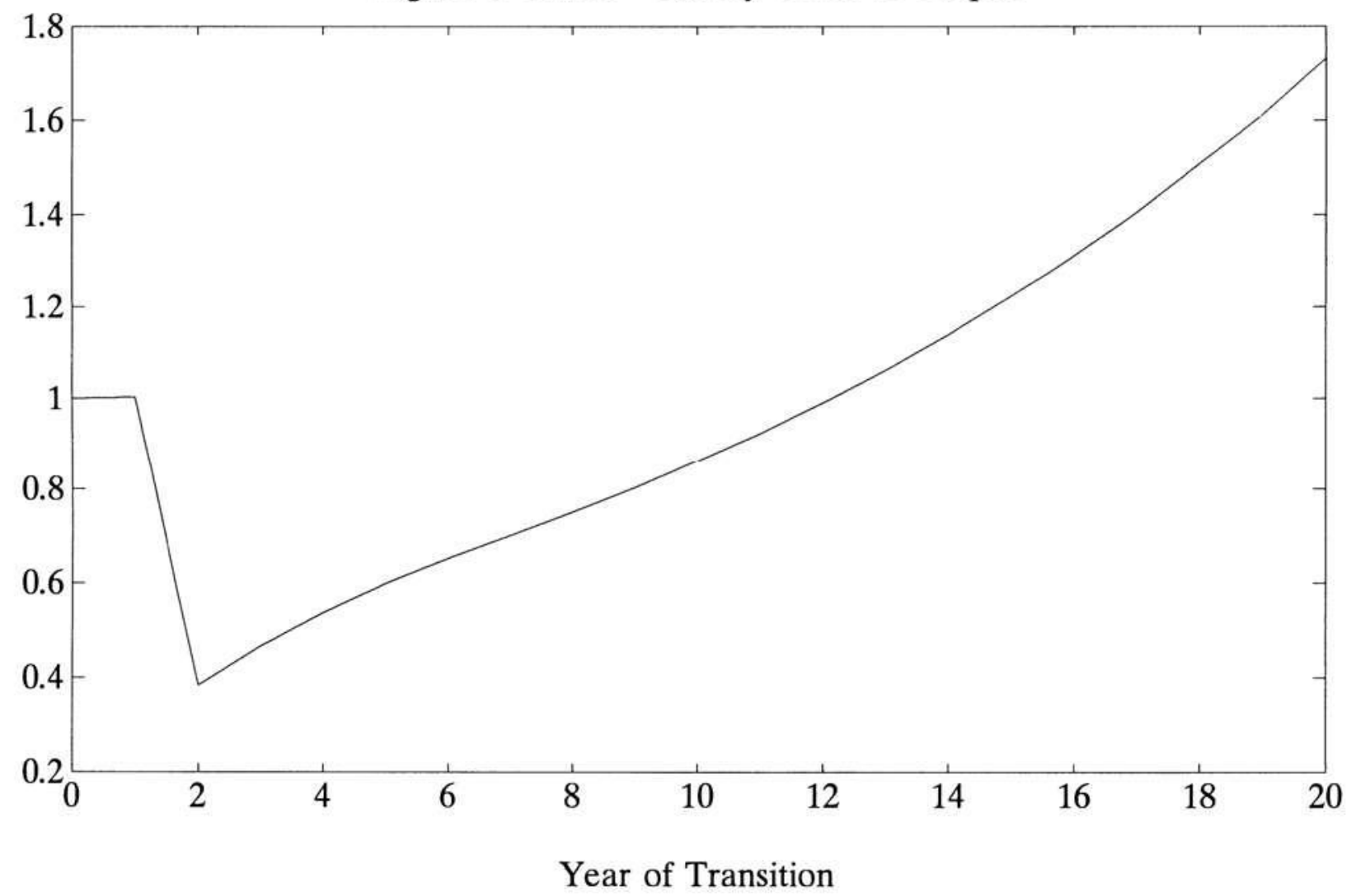


Figure 5: Russia - Twenty Years of $\mathrm{c} / \mathrm{Y}$ and $\mathrm{x} / \mathrm{Y}$

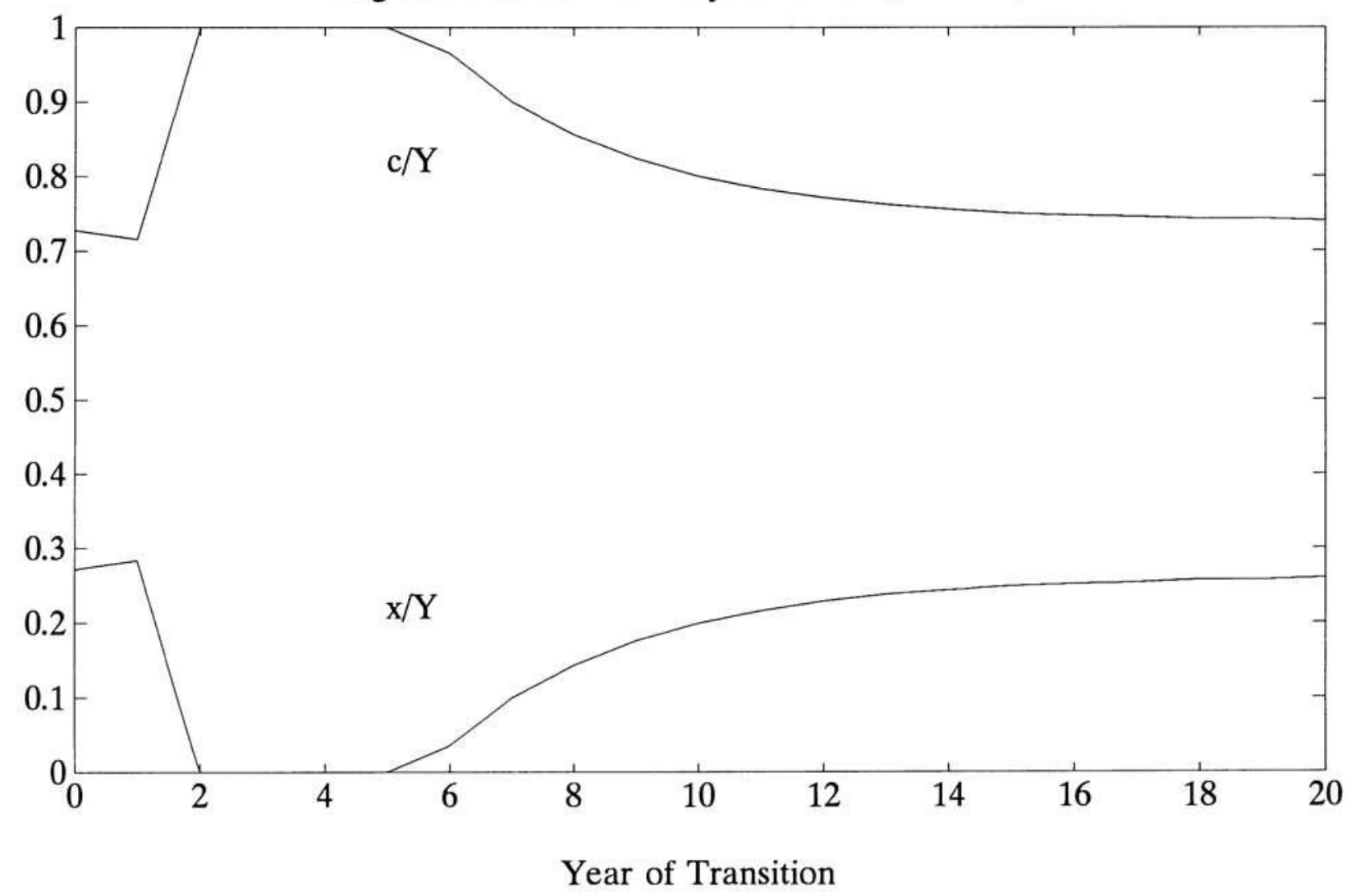

Figure 6: Ratio of Russian and U.S. Output

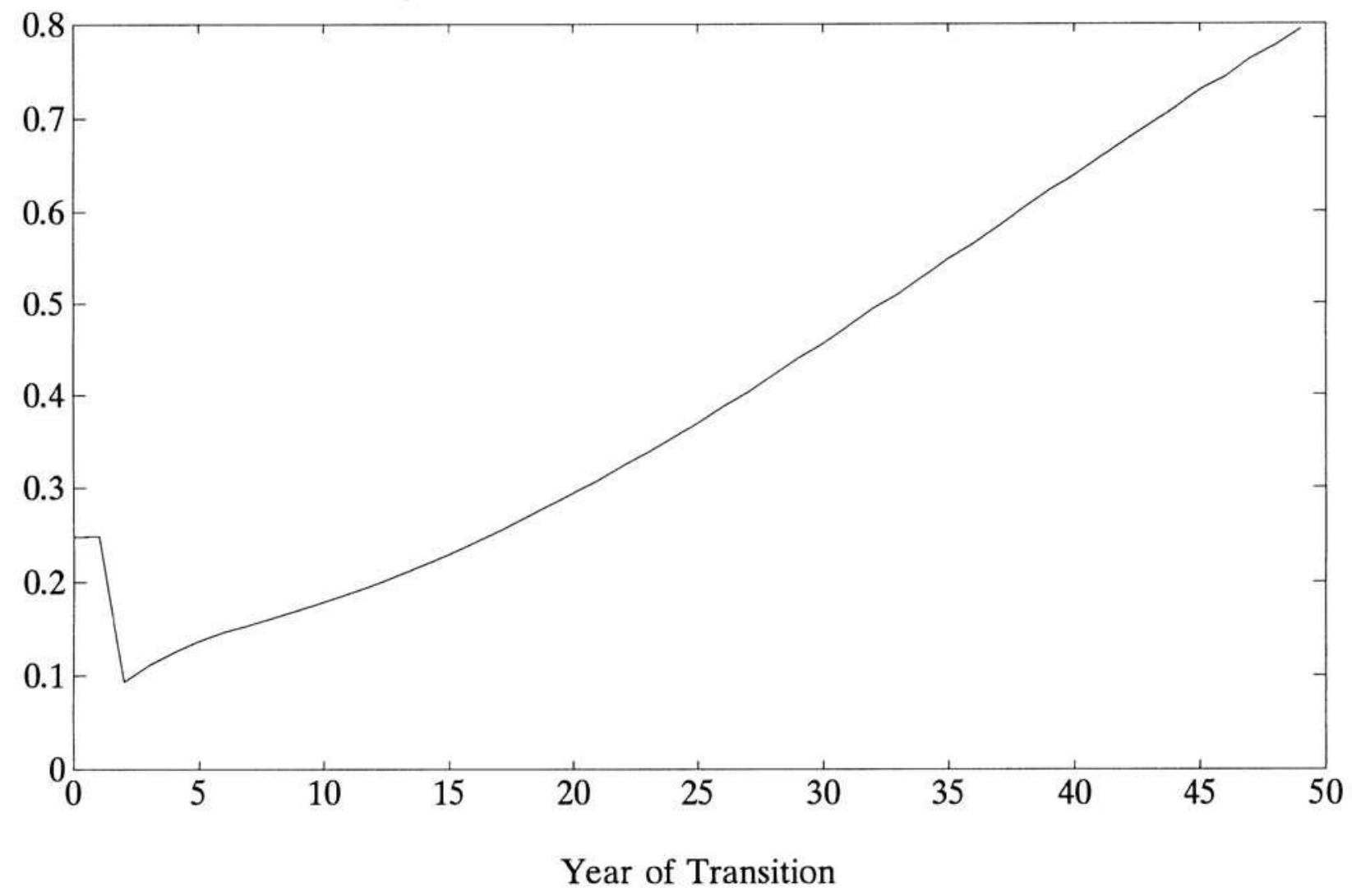


Figure 7: Russia - Cutoff Rules During Transition

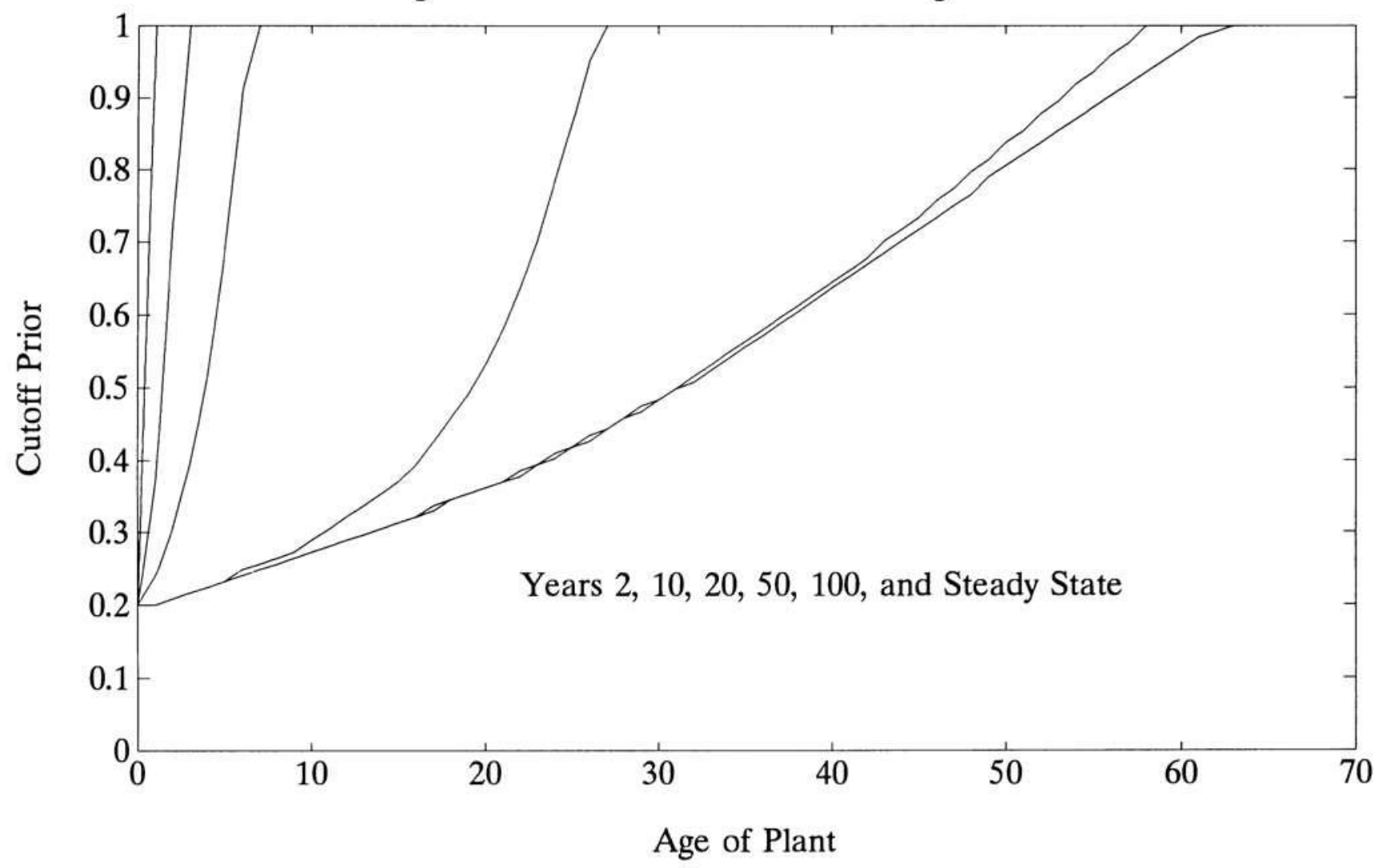

Figure 8: Russia - Frontier Technolgy, Info. Capital, and TFP

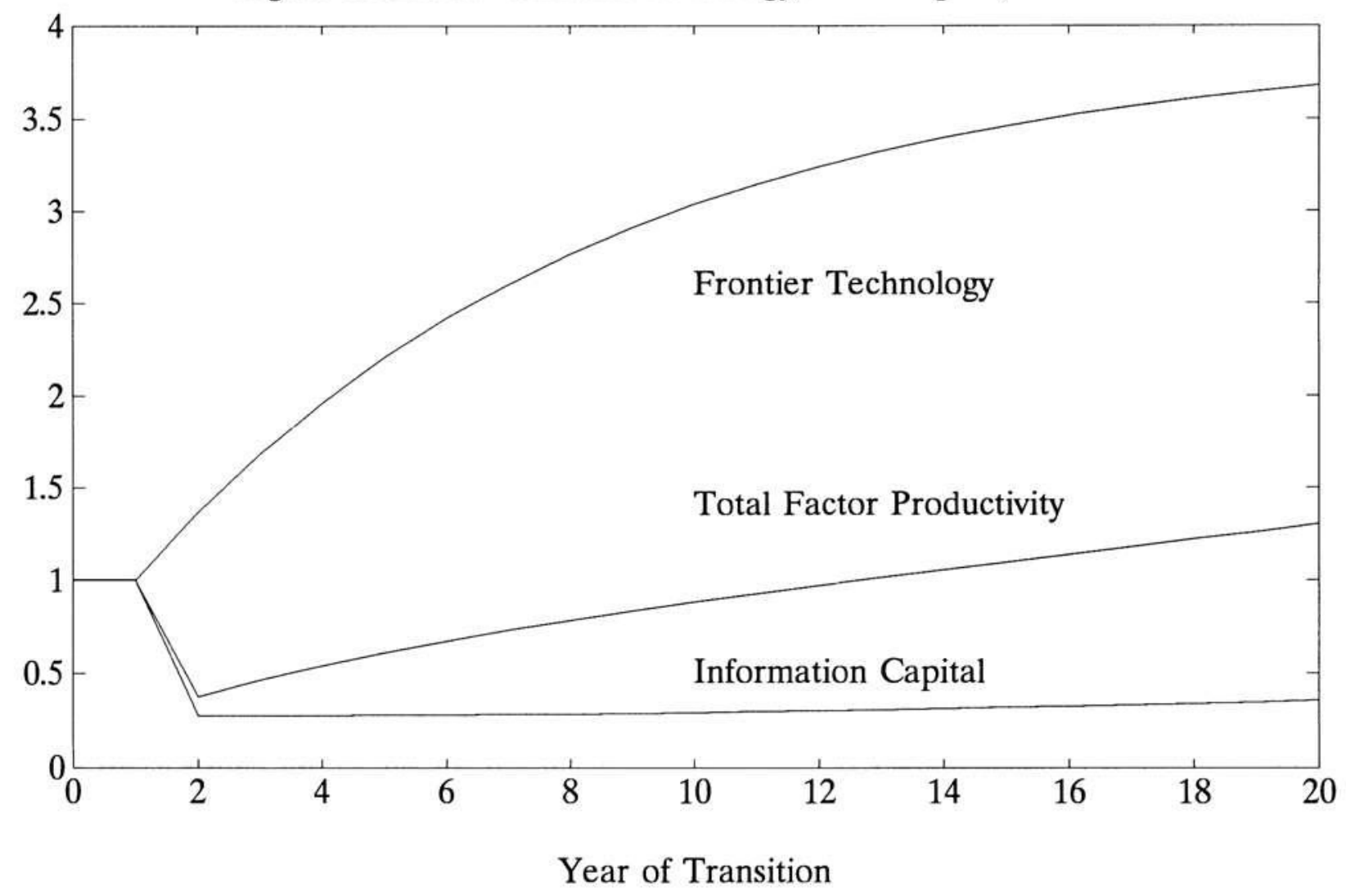


Figure 9: Japan and Russia - Twenty Years of Output

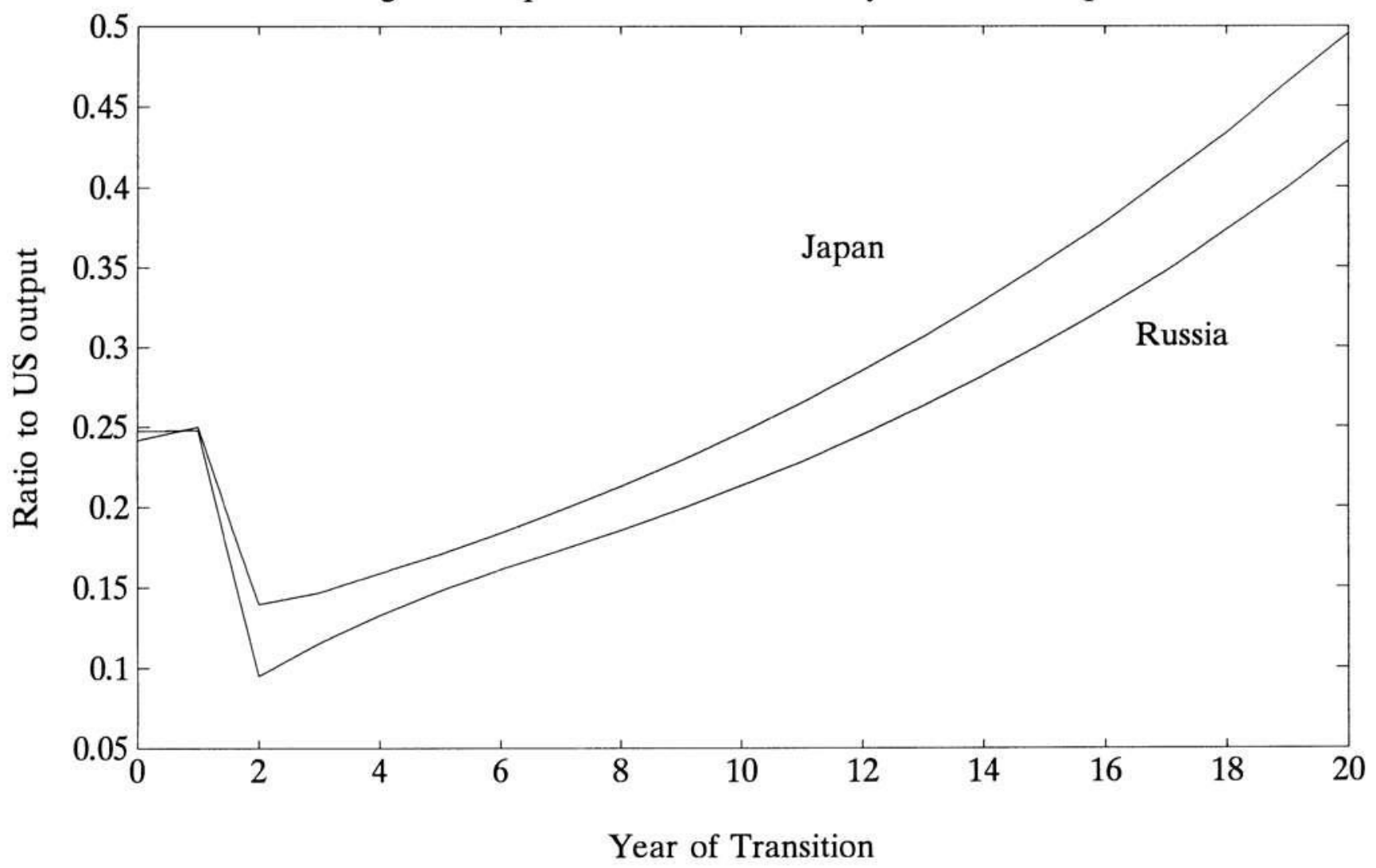

Figure 10: Japan - Twenty Years of $\mathrm{c} / \mathrm{Y}$ and $\mathrm{x} / \mathrm{Y}$

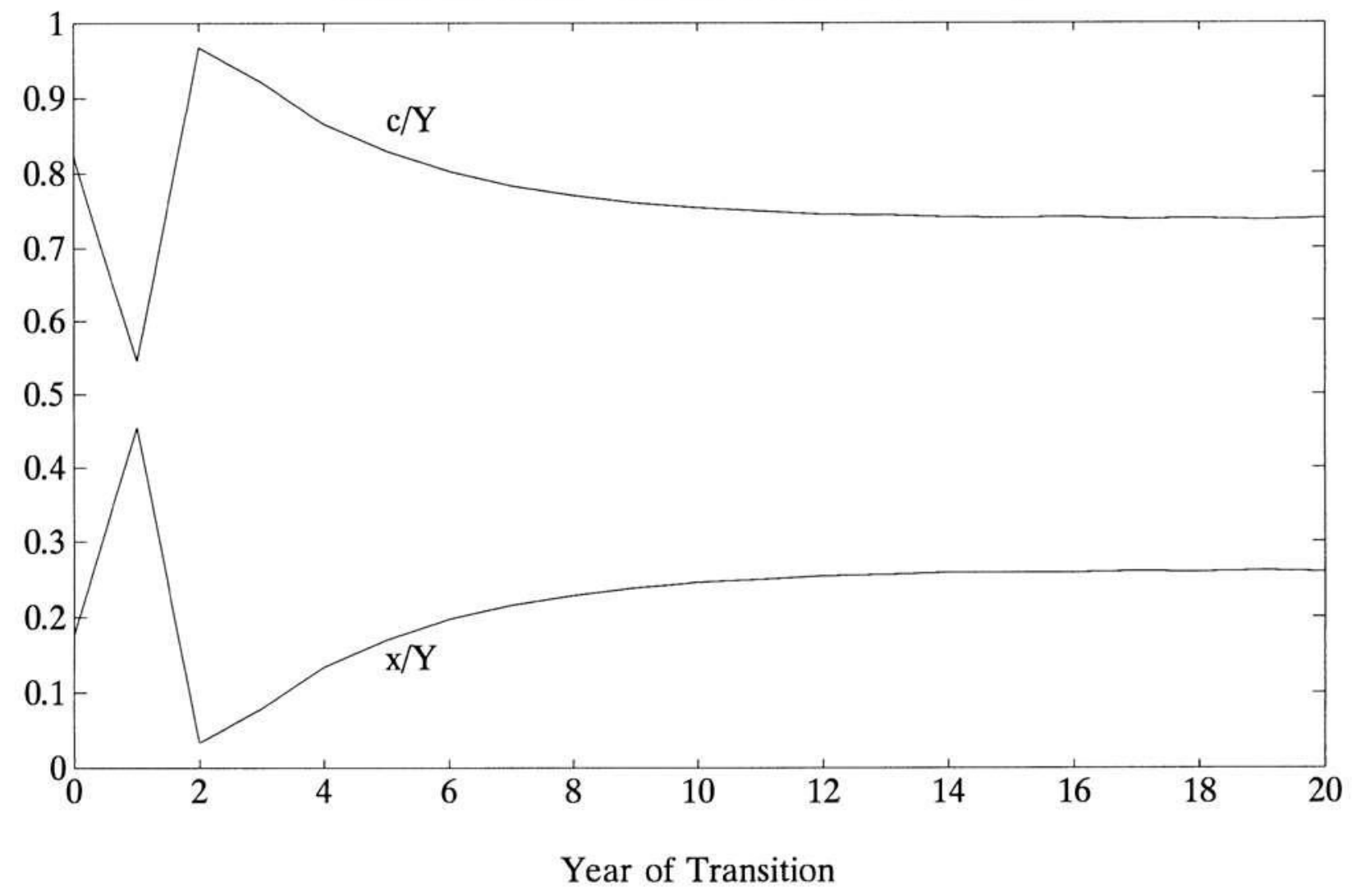


Figure 11: Selection Effect versus S.S. Growth Rate

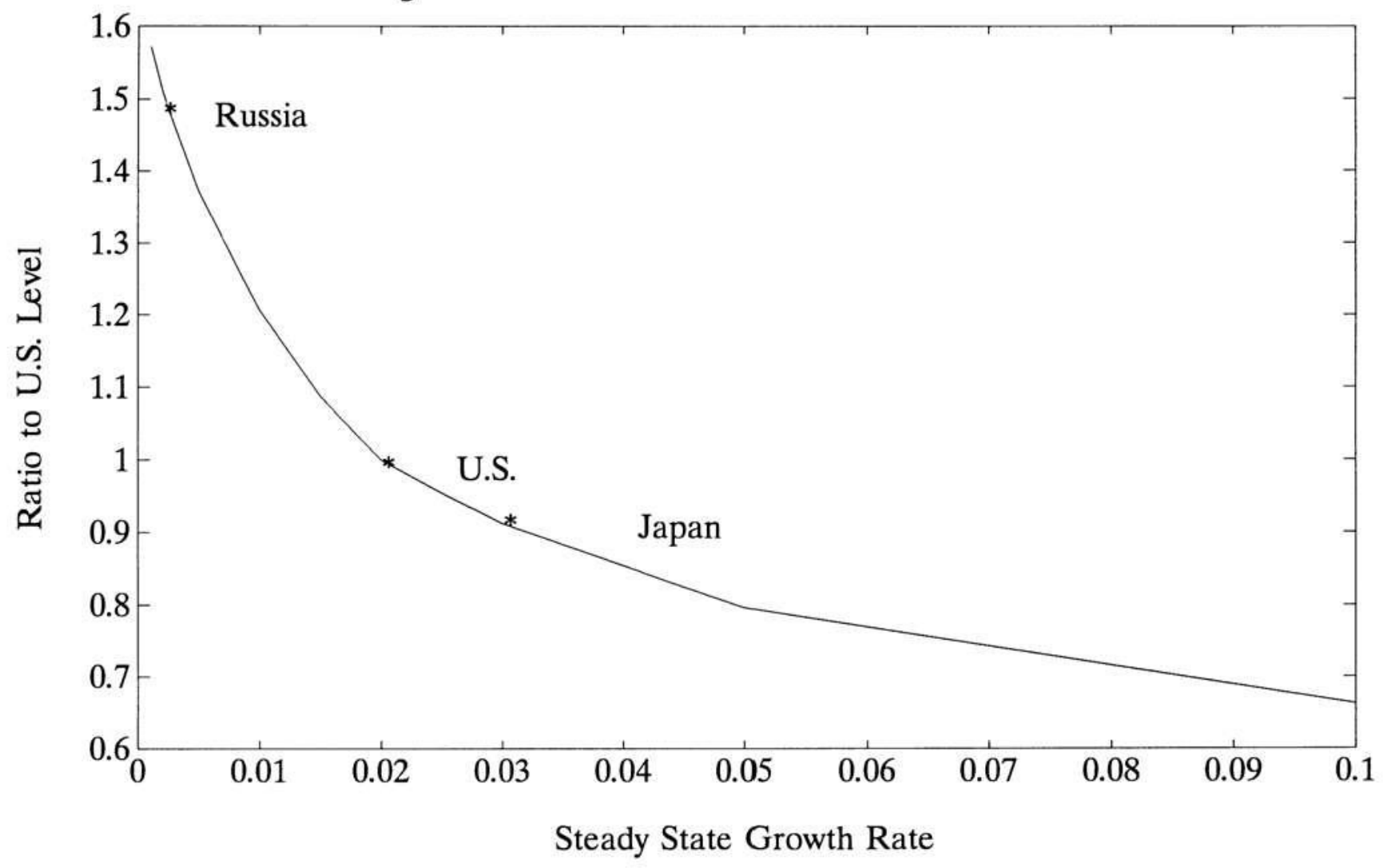

Figure 12: Russian Output With and Without Info. Capital

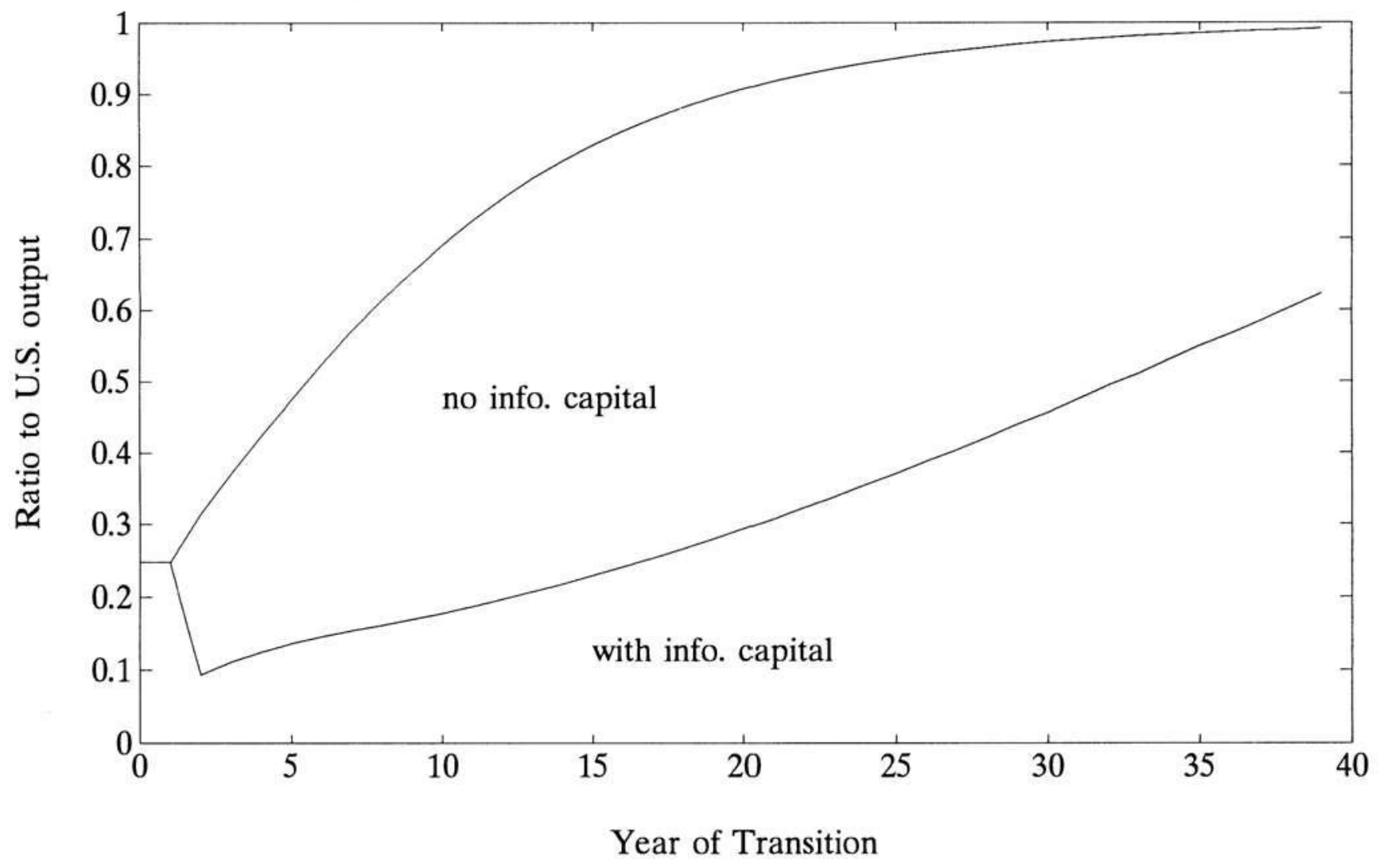

